\title{
Digit ratio (2D:4D): relationship with freestyle swimming performance of adolescent well-trained swimmers
}

\author{
Özen G. ${ }^{1 \mathrm{ACDE}}$, Atar Ö. ${ }^{2 \mathrm{ABE}}$, Koç H. ${ }^{2 \mathrm{ABE}}$ \\ ${ }^{1}$ Department of Physical Education and Sports Teaching, Faculty of Sport Sciences, Çanakkale Onsekiz Mart \\ University, Çanakkale, Turkey. \\ ${ }^{2}$ Department of Coaching Education, Faculty of Sport Sciences, Çanakkale Onsekiz Mart University, Çanakkale, \\ Turkey
}

Authors' Contribution: A - Study design; B - Data collection; C - Statistical analysis; D - Manuscript Preparation; E - Funds Collection.

\begin{abstract}
Purpose: $\quad$ The purpose of this study was to determine whether there was a relationship between the digit ratios and freestyle swimming performance of adolescent well-trained swimmers.

Material: $\quad$ Twenty-two well-trained male swimmers who had at least 3 years of swim training experience were recruited as participants. The participants' mean age was $14.1 \pm 1.5$ years, body height was $164.5 \pm 11.3 \mathrm{~cm}$, and body mass was $54.4 \pm 11.2 \mathrm{~kg}$. Participants' body height, mass, index finger (2D) and ring finger (4D) lengths were measured and digit ratio (2D:4D) and body mass index of participants was calculated. To determine the swimming performance of participants, the short $(50 \mathrm{~m}$ and $100 \mathrm{~m})$ and middle $(200 \mathrm{~m}$ and $400 \mathrm{~m})$ distance freestyle time-trial swimming tests were performed on participants. The association between the 2D:4D ratio and the swimming performance were determined by the Pearson correlation coefficient.

Results: $\quad$ Our findings indicated that there were strong negative correlations $(r>.50)$ between the mean of BMI and swimming times of adolescent swimmers. $(p>.05)$. However, result of this study revealed no relationship between the digit ratio (2D:4D) and swimming performance in adolescent swimmers. $(p>.05)$.

Conclusions: As a result, it may be stated that the 2D:4D ratio of swimmers is not a major parameter in predicting swimming performance for adolescent swimmers.

Keywords: athlete, digit ratio, performance, sport, swimming.
\end{abstract}

\section{Introduction}

Digit ratio (2D:4D) is the proportion between the length of the 4th finger to that of 2 nd finger of the hand [1]. Scientific researchers revealed that the digit ratio is a predictive marker which may reflect the exposure and sensitivity to prenatal androgen. They reported that there was a link between prenatal androgen exposure and digit growth [2]. Digit ratio is negatively associated with prenatal testosterone, but positively with estrogen exposure. These correlations are used to estimate the production of testosterone and estrogen in the gonads [3]. 2D:4D digit ratio has been proposed as a putative prenatal testosterone marker studied in various fields of scientific research [4]. Current studies have investigated whether there were associations between 2D:4D ratio and a wide range of physical, mental and social skills [5].

Digit ratio is one of the best indicators of the level of testosterone and are used as a noninvasive method to assess the level of testosterone on the body [3]. Additionally, the results of digit ratio researches revealed that digits of right hand being a more sensitive indicator to predict the level of testosterone on the body due to the influence of prenatal exposure to testosterone $[1,6]$. Testosterone is an androgenic sex hormone and one of the most important hormones that assist with muscular growth, thrive, and muscle damage repairs on the human body $[2,7]$. Numerous cross-sectional studies of the 2D:4D ratios have reported the digit ratios lower in men compared to women because men had a higher testosterone level than (c) Özen G., Atar Ö., Koç H., 2019

doi:10.15561/18189172.2019.0307 women [8]. In the sports science and medicine literature, it is fairly well-known the effect of testosterone on physical performance of both male and female athletes $[2,6]$. Scientific studies suggested that the higher level of testosterone on the body can lead to increase athletic performance in various sports disciplines such as; team handball, soccer, skiing, rugby [6, 9-12]. Some researcher who investigated athletes' digit ratio found a relationship between digit ratio and athletic performance, but others not found $[13,14]$. Therefore, researchers are still arguing over the correlation between digit ratio and athletic performance.

Until today, most of the studies published on this topic have focused on the relationship between athletic performance and digit ratios in adult athletes [2, 9, 11]. A few researchers studied the relationship between athletic performance and digit ratios of adolescent athletes $[15,16]$. Adolescence is a period when male testosterone hormone is most secreted [17]. In this regard, the investigation of the relationship between the digit ratio and athletic performance during this period may provide important findings. To this end, the purpose of this study was to determine whether there was a relationship between digit ratio with short and middle distance freestyle swimming performance of adolescent well-trained swimmers.

\section{Materials and Methods}

Subjects

Twenty-two male well-trained swimmers who had at least 3 years of swim training experience were recruited as 
participants. The objective and the procedures of this study were explained to all participants and their parents. They voluntarily consented to participate in this study. Written informed consent was obtained from each participant as well as their parents before the study commenced. The inclusion criteria of this study were: having an age between 12 and 16 years, being healthy and well-trained male swimmers (at least to be five years swimming). Participants who reported injuries to their index or ring fingers were excluded from this study. All measurements and tests were done in accordance with the principles of the Declaration of Helsinki. The participants' mean age was $14.1 \pm 1.5$ years, body height was $164.5 \pm 11.3 \mathrm{~cm}$, and body mass was $54.4 \pm 11.2 \mathrm{~kg}$. Also, all the participants were right-handed. Anthropometric characteristics of participants are described in Table 1.

Data Collection

\section{Anthropometry and body composition}

The ages of all participants were calculated from the date of birth on their national identity cards. Participants' body height $(\mathrm{cm})$ was measured to the nearest $0.1 \mathrm{~cm}$ using a stadiometer, and body mass $(\mathrm{kg})$ was measured with minimal clothing to the nearest $0.1 \mathrm{~kg}$ a digital body weight scale and the body mass index (BMI, $\mathrm{kg}$ / $\mathrm{m} 2$ ) calculated using the following formula: body mass $(\mathrm{kg})$ / body height2 (m). In order to determine digit ratios (2D:4D) of participants, the length of the 2nd (index) and 4th (ring) fingers were measured directly on the ventral surface of right hand from the crease proximal to the palm to the tip of the finger. Digital callipers with an accuracy of $0.01 \mathrm{~mm}$ (Mitutoyo Absolute 700-113-10, Mitutoyo America Corp, Plymouth, Mich) were used for digit length measurements by a specialist physiotherapist. Digit measurements were made twice, and the average was computed. In order to eliminate bias due to interobserver errors, all digits measurements were made by one physiotherapist. The $2 \mathrm{D}: 4 \mathrm{D}$ ratio of participants was computed by dividing the length of the $2 \mathrm{D}$ by that of the 4D.

\section{Swimming Performance Tests}

The swimmers tested to determine the short $(50 \mathrm{~m}$ and $100 \mathrm{~m})$ and middle $(200 \mathrm{~m}$ and $400 \mathrm{~m})$ distance timetrial swimming performance using freestyle only. All of the performance tests were applied in the competition season. Their swimming performance was assessed over maximal 50, 100, 200, and $400 \mathrm{~m}$ freestyle swimming in a 50-m long course indoor pool (indoor temperature, $25^{\circ} \mathrm{C}$, water temperature, $27^{\circ} \mathrm{C}$ and humidity $60 \%$ ). Each swimming performance test was performed with a dive start and in the swimmer's best stroke. Swimming tests were performed in two separate days with a break of one day between testing for adequate recovery participants. The first day, participants completed 50, 100, and 200 $\mathrm{m}$ swimming performance tests and then the second day completed $400 \mathrm{~m}$ tests. All subjects performed a standardized 5-min warm-up prior to performance tests. Total recovery time between 50,100 and $200 \mathrm{~m}$ tests was $10 \mathrm{~min}$. Their swimming time was recorded using an Omega digital stopwatch with one-hundredth-of-a-second accuracy by two swimming referees. Measurements were done in accordance with ethical principles, and all the tests were conducted by the same person. The testing procedure is standardized for all swimmers.

\section{Statistical Analysis}

Statistical analyses were performed with SPSS Version 15 statistic software package (SPSS Inc., Chicago, IL, USA). The results are given as means (M) and standard deviation (SD). Shapiro-Wilk W tests within normality analysis were used to determine that data was acceptable with regard to homogeneity. As variances showed a normal distribution, the association between the 2D:4D ratio and the swimming performance were determined by the Pearson correlation coefficient. The Pearson correlation coefficients were classified into three levels: high correlation $(>0.50)$, medium correlation $(>0.30$ - 0.49), and low correlation $(\leq 0.30)$. Inter-observer agreement for the first and second measurements of 2D:4D were evaluated using Cohen's kappa coefficient statistic ( $\kappa)$ with single-score intraclass correlation coefficients. The significance level was set at $5 \%$ for all inferential statistics.

\section{Results}

In order to assess the repeatability of digit length measurements, it was calculated Cohen's $\kappa$ statistic. The $\kappa$ statistic for the measurements of 2D:4D showed a high intra-class correlation coefficient $(r=0.98)$. Digits length from the results of the first measurements strongly correlated with the results recorded from second measurements $(\kappa>0.80)$.

Table 2 displays the mean, minimum, maximum values and standard deviations for the swimming time at different distances. According to the data from Table 2, it was seen participants' the mean of the $2 \mathrm{D}$ length $(71.5 \pm 6.1$ $\mathrm{mm})$ were higher than their $4 \mathrm{D}$ length $(74.8 \pm 6.3) \mathrm{mm}$. The mean of participants' digit ratio (2D:4D) was $0.96 \pm 0.4$ (ranged 0.87-1.05).

Table 3 demonstrates the associations between digit ratios (2D:4D) and swimming performance on various distances of participants. The means of both 2D and 4D

Table 1. Anthropometric characteristics of the participants.

\begin{tabular}{llllll}
\hline Variables & $\mathbf{n}$ & Min. & Max. & Mean & SD \\
\hline Age $($ year) & 22 & 11 & 16 & 14.1 & 1.5 \\
Height $(\mathrm{cm})$ & 22 & 141 & 183 & 164.5 & 11.3 \\
Weight $(\mathrm{kg})$ & 22 & 35 & 74.8 & 54.4 & 11.2 \\
BMI $\left(\mathrm{kg} / \mathrm{m}^{2}\right)$ & 22 & 17 & 24 & 19.9 & 1.9 \\
\hline
\end{tabular}


lengths were negatively correlated with 50, 100, 200 and $400 \mathrm{~m}$ swimming time $(\mathrm{p}<.05)$. There were no relationships between $2 \mathrm{D}: 4 \mathrm{D}$ ratios and swimming time in 50,100, 200 and $400 \mathrm{~m}(\mathrm{p}>.05)$. However, 2D:4D ratio significantly correlated with BMI of participants. The mean of participants' BMI negatively correlated 50, 100,200 , and $400 \mathrm{~m}$ swimming time.

\section{Discussion}

The current study addresses this issue by examining relationships between the digit ratio (2D:4D) and swimming performance in male adolescent well-trained swimmers. Scientific researches revealed that there is a negative correlation between digit ratio and prenatal testosterone, but a positive correlation with estrogen exposure $[2,8]$. It is generally accepted that low 2D:4D ratio is linked with a higher level of testosterone [18]. The importance of testosterone hormone for the accrual of muscle mass or strength is indicated by a number of studies showing links between the level of testosterone and body composition and/or muscle mass in later life [1, 19]. In this connection, much of the research investigating the links between digit ratios and athletic performance has reported that elite athletes have low 2D:4D ratio (ranged 0.90-1.00) $[2,11,12,20]$. Similarly, adolescent well- trained swimmers who participated in this study also had a low digit ratio $(0.96 \pm 0.04)$. This result of the present study is in good agreement with the recent literature.

Our findings indicated that there were strong negative correlations $(\mathrm{r}>.50)$ between the mean of BMI and swimming times of adolescent swimmers. As expected, many researchers also have found that swimmers with low BMI have better swimming performance time [16]. In addition, 2D:4D ratio of participants was positively correlated with BMI $(p<.05)$. Scientific researches have revealed that the high prenatal testosterone levels strongly related to higher muscle mass and lower fat mass in adulthood $[1,19]$. In literature, the lower 2D:4D ratio are thought to signal the higher pubertal or adult testosterone levels and high BMI reflects low testosterone levels [21]. For adolescent swimmers in this study is in agreement with the idea that lower BMI would be associated with higher testosterone and lower 2D:4D ratio in athletes.

Nowadays the relationships of digit ratios (2D:4D) with physical, psychological characteristics and athletic performance is one of the most popular issues in various scientific fields $[22,23]$. Thus, we wanted to study whether there was a relationship between digit ratio (2D:4D) and swimming performance. General characteristics of successful swimmers include speed, endurance, and

Table 2. The swimming performance data of participants.

\begin{tabular}{lllll}
\hline Variables & Min. & Max. & Mean & SD \\
\hline 2D (mm) & 55.6 & 79.0 & 71.5 & 6.1 \\
4D (mm) & 58.8 & 85.4 & 74.8 & 6.3 \\
2D:4D & 0.87 & 1.05 & 0.96 & 0.04 \\
50 m swimming time (s) & 26.1 & 35.0 & 29.3 & 2.4 \\
100 m swimming time (s) & 56.0 & 60.2 & 59.2 & 1.2 \\
200 m swimming time (min) & 2.01 & 2.43 & 2.15 & 0.13 \\
400 m swimming time (min) & 4.12 & 5.40 & 4.53 & 0.44 \\
\hline
\end{tabular}

Note: $*$ p $<.05, * * ; p<.01$

Table 3. Pearson correlation coefficient analysis of 2D:4D ratio and swimming performance time of participants.

\begin{tabular}{|c|c|c|c|c|c|c|c|}
\hline Variables & & 2D:4D & BMI & $50 \mathrm{~m}$ & $100 \mathrm{~m}$ & $200 \mathrm{~m}$ & $400 \mathrm{~m}$ \\
\hline \multirow{2}{*}{ 2D:4D } & $r$ & \multirow{2}{*}{1} & $.362 *$ & -046 & .081 & -.160 & -.192 \\
\hline & $p$ & & .049 & .420 & .368 & .238 & .196 \\
\hline \multirow{2}{*}{$\mathrm{BMI}$} & $r$ & - & \multirow{2}{*}{1} & $-.618 * *$ & $-.599 * *$ & $-.565 * *$ & $-.620 * *$ \\
\hline & $p$ & - & & .001 & .003 & .003 & .001 \\
\hline \multirow{2}{*}{$50 \mathrm{~m}$} & $r$ & - & - & \multirow{2}{*}{1} & $.767^{* *}$ & $.881^{* *}$ & $.829 * *$ \\
\hline & $p$ & - & - & & .000 & .000 & .000 \\
\hline \multirow{2}{*}{$100 \mathrm{~m}$} & $r$ & - & - & - & \multirow{2}{*}{1} & $.576 * *$ & $.578 * *$ \\
\hline & $p$ & - & - & - & & .004 & .004 \\
\hline \multirow{2}{*}{$200 \mathrm{~m}$} & $r$ & - & - & - & - & \multirow{2}{*}{1} & $.810^{* *}$ \\
\hline & $p$ & - & - & - & - & & .000 \\
\hline \multirow{2}{*}{$400 \mathrm{~m}$} & $r$ & - & - & - & - & - & \multirow[b]{2}{*}{1} \\
\hline & $p$ & - & - & - & - & - & \\
\hline
\end{tabular}

Note: $* ; p<.05, * * ; p .01$ 
strength [24]. It is generally considered that the level of testosterone on body influence the improve speed, endurance, muscular strength, and body composition [7]. Both the level of testosterone and physical performance increases rapidly during adolescence [17]. For this reason, examining the relationship between digit ratio and athletic performance in adolescence period may provide more reliable and important findings. The main findings presented in this study show that the low digit ratio is not related to better performance in a freestyle swimming requiring major energetic contributions from both aerobic and anaerobic systems. In literature, a study completed by Voracek et al., 2010 demonstrated that relationships between the digit ratio and fencing success were absent in male fencers [8]. In the study of Lombardo, Otieno and Heiss have been found no significant differences between athletes and non-athletes in digit ratios [25]. Similarly, Peeters and Claessens reported the digit ratio (2D:4D) is not a discriminating parameter for artistic gymnastics performance [26]. Celik et al., also found no relationship between the 2D:4D ratio and physical performance level in master athletes [13]. Like our findings, another researcher Jia who examined the connection between the 2D:4D ratio and throwing ability of athletes in sports undergraduate have reported a decrease 2D: 4D digit ratio did not correlate significantly with sports performance [27]. Our results were consistent with these researchers who proclaimed no association between the digit ratio and athletic performance. It is widely known that many factors such as: anthropometric and physiological characteristics, genetic, technical and tactical ability, nutrition, sleep, psychology, experience, and external factors such as; coaches, training methods, altitude, ambient temperature, relative humidity etc. and/or combining these factors play a critical role in the performance of young athletes and have the potential to influence, positively or negatively, their sportive performance. Taken together, these factors also might mask a potential association between digit ratio and athletic performance in many sports.

Recently, a growing literature has emerged from studies claiming there is a meaningful negative relationship between the digit ratio and physical performance in both athletic and sedentary group [2, 6, 9, 11]. These studies have suggested results opposite to our findings. Based on their results, digit ratios and finger lengths can be considered as a main predictive parameter for talent selection or athlete performance in children and young athletes. However, according to the results of the present study and other studies which claimed to be contrary to their findings, it can be said that making such a prediction by taking the digit ratios of athletes into consideration can lead to potential inaccuracy.

\section{Conclusion}

Finally, the result of this study revealed no relationship between the digit ratio (2D:4D) and swimming performance in adolescent swimmers. In this respect, we may be stated that the 2D:4D ratio of swimmers is not a major parameter in predicting athletic performance. In literature, there are authors, who reported different results about the correlation between the 2D:4D ratio and athletic performance in sports. Therefore, the relationship of athletic performance with digit ratios as a predictive marker of the level free testosterone may remain speculative. Future research should target longterm observation of the link between these parameters in various sports.

\section{Highlights}

- Low digit ratio is not related to better freestyle swimming performance in adolescent well-trained swimmers.

- There were strong negative correlations between the mean of BMI and swimming times of adolescent swimmers.

- Lower BMI would be associated with higher testosterone and lower 2D:4D ratio in adolescent well-trained swimmers.

\section{Acknowledgment}

We gratefully acknowledge the help of all the participant who took part in the study.

\section{Conflict of interests}

The authors state that there is no conflict of interest.

\section{References}

1. Manning JT, Scutt D, Wilson J, Lewis-Jones DI. The ratio of 2nd to 4th digit length: a predictor of sperm numbers and concentration of testosterone, luteinizing hormone, and oestrogen. Hum Reprod. 1998;13(11):3000- 4. https://doi.org/10.1093/humrep/13.11.3000

2. Longman D, Stock JT, Wells JC. Digit ratio (2D:4D) and rowing ergometer performance in males and females. Am $J$ Phys Anthropol. 2011;144(3):337- 41. https://doi.org/10.1002/ajpa.21407

3. Lutchmaya S, Baron-Cohen S, Raggatt P, Knickmeyer R, Manning JT. 2nd to 4th digit ratios, fetal testosterone and estradiol. Early Hum Dev. 2004;77:23- 28. https://doi.org/10.1016/j.earlhumdev.2003.12.002

4. McIntyre MH. The use of digit ratios as markers for perinatal androgen action. Reprod Biol Endocrinol, 2006;4: 10-20.
5. Muller DC, Giles GG, Bassett J, Morris HA, Manning JT, Hopper JL, et al. Second to fourth digit ratio (2D:4D) and concentrations of circulating sex hormones in adulthood. Reproductive Biology and Endocrinology 2011;9:57. https://doi.org/10.1186/1477-7827-9-57

6. Tambe MK, Turankar AV., Lingawar S, Dhokane NB, Pophali NP, Kherde PM, Bajaj V. Influence of digit ratio (2D: 4D) on reaction time and athletic sprint performance: A short term pilot study. MedPulse International Journal of Physiology. 2018;5(2):17-21.

7. Liu TC, Kuo $\mathrm{CH}$, Wang PS. Exercise and testosterone. Adaptive Medicine. 2009;1(1):26-31.

8. Voracek M. Special issue preamble: Digit ratio (2D: 4D) and individual differences research. Personality and Individual Differences. 2011;51(4): 367-70. https://doi.org/10.1016/j.paid.2011.04.018 
9. Bennett M, Manning JT, Cook CJ, Kilduff LP. Digit ratio (2D:4D) and performance in elite rugby players. $J$ Sports Sci. 2010;28(13):1415-21. https://doi.org/10.1080/02640414.2010.510143

10.Cardinale M, Stone MH. Is testosterone influencing explosive performance?. J Strength Cond Res. 2006;20(1):103-7.

11.Eler N, Eler S. 2D: 4D, Lateralization and Strength in Handball Players. Journal of Education and Training Studies. 2018;6(5):170-8. https://doi.org/10.11114/jets.v6i5.3220

12.Kilduff L, Cook CJ, Bennett M, Crewther B, Bracken RM, Manning J. Right- left digit ratio (2D: 4D) predicts free testosterone levels associated with a physical challenge. $J$ Sports Sci. 2013;31(6):677-83. https://doi.org/10.1080/02640414.2012.747690

13.Celik A, Aksu F, Tunar M, Dasdan AEN, Topacoğlu H. Effects of digit ratio of master athletes on sporting achievement levels. DEÜ Tip Fakültesi Dergisi. 2010;24(3):89-93.

14.Honekopp J, Schuster M. A meta-analysis on 2D: 4D and athletic prowess: Substantial relationships but neither hand out-predicts the other. Personality and Individual Differences. 2010;48(1):4-10. https://doi.org/10.1016/j.paid.2009.08.009

15.Hull MJ, Schranz NK, Manning JT, Tomkinson GR. Relationships between digit ratio (2D: 4D) and female competitive rowing performance. Am J Hum Biol. 2015;27(2):157-63. https://doi.org/10.1002/ajhb.22627

16.Jurimae T, Voracek M, Jurimae J, Latt E, Haljaste K, Saar $\mathrm{M}$, Purge $\mathrm{P}$. Relationships between finger-length ratios, ghrelin, leptin, IGF axis, and sex steroids in young male and female swimmers. Eur J Appl Physiol. 2008;104(3):523-29. https://doi.org/10.1007/s00421-008-0801-z

17.Ramos E, Frontera WR, Llopart A, Feliciano D. Muscle strength and hormonal levels in adolescents: gender related differences. Int J Sports Med. 1998;9(08):526-31. https://doi.org/10.1055/s-2007-971955

18.Garcia-Cruz E, Huguet J, Piqueras M, Ribal MJ, Alcaraz A. Second to fourth digit ratio, adult testosterone level and testosterone deficiency. BJU Int. 2012;109(2):266-71. https://doi.org/10.1111/j.1464-410X.2011.10249.x

19.Holzapfel SD, Chomentowski III PJ, Summers LAM, Sabin MJ. The relationship between digit ratio (2D:4D), VO2max, ventilatory threshold, and running performance. International Journal of Sports Sciences \& Fitness. 2016;6(1):1-30.

20.Bescos R. Esteve M, Porta J, Mateu M, Irurtia A, Voracek M. Prenatal programming of sporting success: Associations of digit ratio (2D:4D), a putative marker for prenatal androgen action, with world rankings in female fencers, $J$ Sports Sci. 2009;27(6):625-32. https://doi.org/10.1080/02640410802707029

21.Van Dongen S. Second to fourth digit ratio in relation to age, BMI and life history in a population of young adults: a set of unexpected results. Journal of Negative Results. 2009;6:1-7.

22.Balc1 RS, Acıkgoz AK, Goker P, Bozkir MG. The Relationship of finger length ratios (2D:4D) with quantitative, verbal talent and anthropometric parameters. International Journal of Morphology. 2018;6(1):310-18. https://doi.org/10.4067/S0717-95022018000100310

23.Dyer M, Short SE, Short M, Manning JT, Tomkinson GR. Relationships between the second to fourth digit ratio (2D: 4D) and game-related statistics in semi-professional female basketball players. Am J Hum Biol. 2018;30(1):e23070. https://doi.org/10.1002/ajhb.23070

24.Smith DJ, Norris SR, Hogg JM. Performance evaluation of swimmers: scientific tools. Sports Med. 2002;32(9):539-54. https://doi.org/10.2165/00007256-200232090-00001

25.Lombardo MP, Otieno S, Heiss A. College-aged women in the United States that play overhand throwing sports have masculine digit ratios. PloS One. 2018;13(9):e0203685. https://doi.org/10.1371/journal.pone.0203685

26.Peeters MW, Claessens AL. Digit ratio (2D: 4D) and competition level in world-class female gymnasts. $J$ Sports Sci. 2013;31(12):1302-11.

27.Jia J. Research on the relationship of the digit ratio and the throwing ability of throwing athlete in sports undergraduate college. Bio Thecnology An Indian Journal. 2014;10(9):3698703.

\section{Information about the authors:}

Özen G.; (Corresponding author); http://orcid.org/0000-0001-5756-653X; gokmenozen44@gmail.com; Department of Physical Education and Sports Teaching, Faculty of Sport Sciences, Çanakkale Onsekiz Mart University ; Sports Science Faculty 17000 Çanakkale, Turkey.

Atar Ö.; http://orcid.org/0000-0001-7941-2865; ozdemir@comu.edu.tr; Department of Coaching Education, Faculty of Sport Sciences, Çanakkale Onsekiz Mart University; Sports Science Faculty 17000 Çanakkale, Turkey.

Koç H.; http://orcid.org/0000-0003-2867-9775; hurmuzkoc@gmail.com; Department of Coaching Education, Faculty of Sport Sciences, Çanakkale Onsekiz Mart University; Sports Science Faculty17000 Çanakkale, Turkey.

Cite this article as:

Özen G, Atar Ö, Koç H. Digit ratio (2D:4D): relationship with freestyle swimming performance of adolescent well-trained swimmers. Pedagogics, psychology, medical-biological problems of physical training and sports, 2019;23(3):150-154. https://doi.org/10.15561/18189172.2019.0307

This is an Open Access article distributed under the terms of the Creative Commons Attribution License, which permits unrestricted use, distribution, and reproduction in any medium, provided the original work is properly cited (http://creativecommons.org/licenses/by/4.0/deed.en).

Received: 02.04.2019

Accepted: 29.04.2019; Published: 29.06.2019 